\title{
THEORETICAL MODEL OF A THIN-FILM VACUUM FREEZING ICE PRODUCTION (VFIP) METHOD
}

\author{
Heng-I Lin and Shyan-Fu Chou* \\ Department of Mechanical Engineering \\ National Taiwan University \\ Taipei, Taiwan 106, R.O.C.
}

Key Words: vacuum freezing, ice growth rate, latent heat coupling.

\begin{abstract}
A new vacuum freezing ice production (VFIP) method based on the solid-liquid-vapor multiple phase transformation and the latent-heat coupling mechanism is introduced in the present study. Coupled heat and mass flux equations based on irreversible thermodynamics have been applied to depict the ice growing phenomenon under vacuum, and to derive an equation for its growth rate. Ice growth rates of the VFIP model determined are much higher than the ones in the conventional freezing model which is for ice production at atmospheric pressure. The concept of equivalent ice-layer thickness $\delta_{e q}$ with respect to the specific water film thickness $\delta_{l}$, and a design guideline for optimal operation are also introduced in the present study. With the unique feature of a spontaneous temperature gradient developed inside the ice layer of VFIP, an extremely fast and energy-saving ice-block production method is found to overcome the disadvantages in energy consumption and ice growth rate of conventional methods.
\end{abstract}

\section{INTRODUCTION}

Ice-blocks used in various situations such as fisheries, the food industry and ice storage air-conditioning systems in the current market are mainly produced by conventional vapor-compression refrigerating systems. The rate of ice production of such systems is extremely slow and the electric power consumption in the process is large. Therefore, a fast, and energy saving method of ice production is yearned for urgently. Vacuum freezing ice production is one of the possible alternatives. A few studies of vacuum freezing to separate solvent from solution, especially water from seawater (Dickey, 1996), have been reported. The methods reported could only produce suspension ice-slurry but not ice-blocks for general applications. Under the demands mentioned above and using the concept of in-situ freezing (Cheng, 1995), an ice-block production method based on the solid-liquid-vapor multiple phase transformation and the latent-heat coupling mechanism is hereby proposed. The new method, named vacuum freezing ice production (VFIP), is presented in this study.

From the phase diagram of water (Fig. 1), a marvelous and unique feature of this VFIP method can be seen in the meta-stable region (Tester and Modell, 1997), i.e. the sub-triple region of water where the pressure is slightly lower than its triple point $(4.58 \mathrm{mmHg})$. In this subtle region, of waterfreezing temperature is higher than that of icesublimation. This characteristic provides a temperature gradient inside the ice layer between the freezing and the sublimation interfaces, and spontaneously creates a driving force needed for heat transport

\footnotetext{
*Correspondence addressee
} 


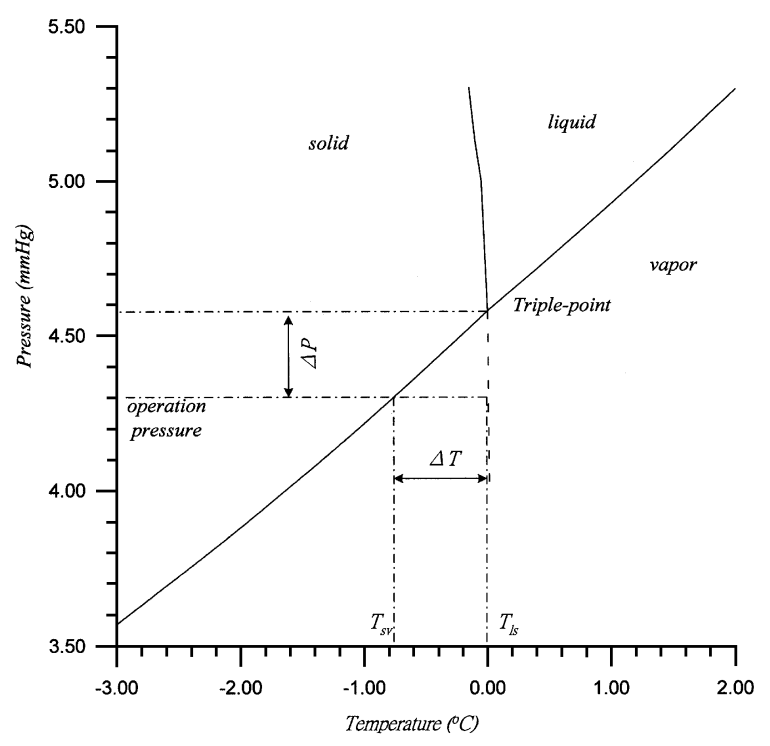

Fig. 1 Phase diagram of pure water near the triple point

during the solidification process. By endeavoring to utilize the spontaneous driving force, the reasons behind the energy-saving, fast-growing VFIP method are revealed.

The anticipated physical phenomena of ice production based on the VFIP method can be explicated as below. Consider a quiescently thin water film trapped in a vacuum chamber with pressure slightly lower than its triple point. Part of the water flashes immediately and ice crystals form spontaneously. After an extremely thin ice layer is formed upon the water film, its thickness starts to increase gradually and the latent heat of freezing is released and transferred by conduction through the ice layer. Consequently, low-pressure water vapor is generated by sublimation of the ice layer surface and carries away the heat of freezing, which is then removed by cooling coils of the operating system immediately. The ice block is thus produced.

For investigating and verifying the complicated heat and mass transport phenomena of vacuum freezing, the present study establishes a new vacuumfreezing model originated from the theorem of irreversible-thermodynamics. The heat and mass transport processes are coupled when the water film is freezing. In the formalism given by irreversible thermodynamics (Kuiken, 1994), the rate of entropy production or entropy dissipation is induced by the uncompensated heat produced by irreversible processes. The ice growth rate of the conventional-freezing process operated under atmospheric pressure generally varies from $3 \times 10^{-7} \mathrm{~m} / \mathrm{s}$ to $1.15 \times 10^{-6} \mathrm{~m} / \mathrm{s}$ with a driving force of 0.2 to $1^{\circ} \mathrm{C}$ (Ratkje and Flesland, 1995; Huige, 1972; Flesland, 1995). With the same

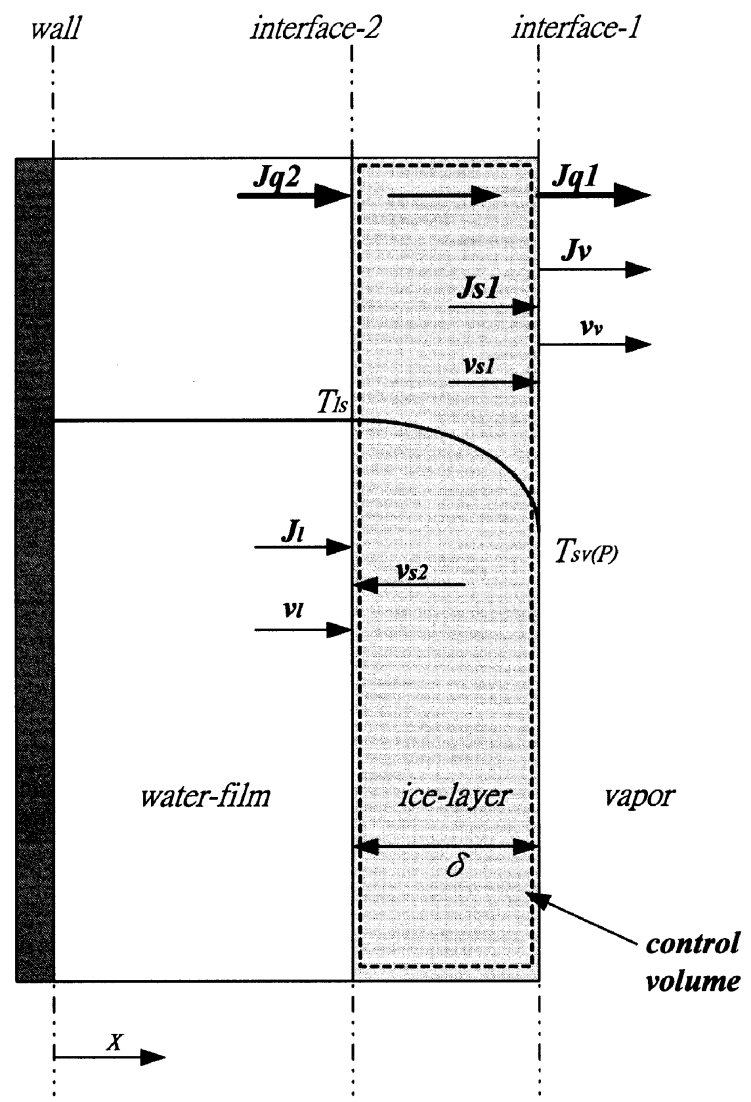

Fig. 2 Theoretical VFIP model

driving force provided, the ice growth rate of the present VFIP method could reach $1.15 \times 10^{-5} \mathrm{~m} / \mathrm{s}$ to $7 \times 10^{-5} \mathrm{~m} / \mathrm{s}$. Apparently, the ice growth rate of the present method is much higher than the former one. Aspirations for an energy-saving, fast-growing ice production method, can, therefore, be achieved.

The essential feature of the herein proposed system is that two interfaces coexist in the working medium, and each interface separates the medium into two regions with different properties. The ice growth rates and the heat transfer coefficients within the region near triple-point are investigated. Moreover, design guidelines for experimental assemblies and industrial procedures in accordance with the results are proposed.

\section{THEOREM}

Figure 2 illustrates the schematic diagram of the VFIP model proposed. Trapped water film attached to the solid wall is under solidification at pressure slightly below its triple point. All the major transport phenomena for such a trapped thin liquid film could be considered to take place in the $\mathrm{x}$-direction, 
i.e. the direction with a significant temperature gradient. The whole water layer is presumably kept at its triple point temperature $\left(0.0099^{\circ} \mathrm{C}\right)$, thus, there is no temperature gradient inside the water film. During the solidifying operation, an extremely thin ice layer is first formed by flash freezing upon the water layer, and low-pressure water vapor is formed immediately by sublimation on the ice surface. Since the operation pressure is slightly below the triple point, the pressure difference developed would spontaneously generate a temperature gradient between the solid-vapor interface and the solid-water interface as depicted in Fig.1. The temperature difference between these two interfaces is therefore considered to be the initial driving force. The VFIP theoretical model is originated from the general assumptions following: (1) the pressure of the control system is kept slightly below the triple point pressure, (2) an extremely thin ice layer has been formed previously, (3) no heat transports into the control system, (4) the process of de-sublimation of the low pressure vapor proceeds with no resistance, (5) all transports take place in the $\mathrm{x}$-direction only.

\section{The Phenomenological Equations}

According to the irreversible process of thermodynamics (Kuiken, 1994), the entropy dissipation per unit time and volume for coupled transport of heat and mass across an interface is

$$
T \cdot \Theta=-J_{q 1} \cdot \nabla \ln T-J_{s 1} \cdot \nabla \mu_{H_{2} O, T}
$$

where, $T$ is the temperature of the controlled system, and $\Theta$ is the entropy production per unit time and unit volume of the controlled system. The heat flux and the mass flux of ice-sublimation are $J_{q 1}$ and $J_{s 1}$ respectively. The heat flux is given in $\left(\mathrm{W} / \mathrm{m}^{2}\right)$ and the mass flux is given in $\left(\mathrm{mol} / \mathrm{m}^{2} \mathrm{~s}\right)$. The thermodynamic driving force for heat transport is the dimensionless quantity $\nabla \ln T$. The chemical driving force for mass transport is the chemical potential gradient $\nabla \mu_{H 2 O, T}$, and the chemical potential is given in $(\mathrm{J} / \mathrm{mol})$.

At interface 1 of Fig. 2, the phenomenological flux equations according to Eq. (1) and across this interface are

$$
\begin{aligned}
& J_{q 1}=-l_{11} \nabla \ln T-l_{12} \nabla \mu_{H_{2} O, T} \\
& J_{s 1}=-l_{21} \nabla \ln T-l_{22} \nabla \mu_{H_{2} O, T}
\end{aligned}
$$

where $l_{i j}$ is the phenomenological coefficient.

The dissipated energy is independent of the frames of reference for the fluxes. The possible frames of reference are indicated by the superscripts: wall, $s$ (for ice layer), and $v$ (for water vapor) respectively,

$$
v_{s l}^{v}=\left(v_{s l}-v_{v}\right)^{\text {wall }}
$$

The mass flux of ice-sublimation according to the entropy production across the interface 1 is:

$$
J_{s 1}=v_{s 1}^{v} \cdot C_{s}=J_{v}
$$

where $C_{s}$ is the concentration $\left(\mathrm{mol} / \mathrm{m}^{3}\right)$ of the ice layer.

The vapor sublimating velocity relative to the wall $v_{v}^{\text {wall }}$, as shown in Fig. 2, is correlated to the surface velocity of the ice $v_{s 1}^{\text {wall }}$ by

$$
\begin{aligned}
v_{v}^{\text {wall }} & =\left|v_{s 1}^{\text {wall }}\right|+\Delta v_{v}=\left|v_{s 1}^{\text {wall }}\right|+v_{s 1}^{\text {wall }} \cdot C_{s}\left(V_{v}-V_{s}\right) \\
& =v_{s 1}^{\text {wall }}\left[1+C_{s}\left(V_{v}-V_{s}\right)\right]
\end{aligned}
$$

The volume augmentation of the vapor side $\left(V_{v}-V_{s}\right)$ during ice sublimating is taken into account, where $V_{v}$ and $V_{s}$ are the partial molar volumes of vapor and ice respectively. It is assumed that all the volume expansion takes place only in the x-direction.

\section{The Coupled Transport of Mass and Heat (Mechanism of Ice-sublimation)}

With negligible effect of surface kinetics at interface 1 , the transported heat may be approximated as the enthalpy difference of sublimation $\Delta H_{s v}$ for $\Delta T$. Therefore, from Eqs. (2) and (3) :

$$
\left(\frac{J_{q 1}}{J_{s 1}}\right)_{\Delta T \cong 0}=\frac{l_{12}}{l_{22}}=\Delta H_{s v}
$$

From Onsager's reciprocal relations (Forland et al., 1988) $l_{12}=l_{21}$, then,

$$
l_{21}=l_{22} \cdot \Delta H_{s v}
$$

After introducing this expression into Eq. (3), the mass flux of ice-sublimation in the $\mathrm{x}$-direction can be expressed as:

$$
J_{s 1}=-l_{22}\left(\frac{\Delta H_{s v}}{T} \cdot \frac{d T}{d x}+\nabla \mu_{H_{2} O, T}\right)
$$

Eq. (9) expresses the flux of ice-sublimation, relative to the sublimation surface, towards the vapor front. The phenomenological coefficient $l_{22}$ can be estimated from diffusion coefficient (Flesland, 1995),

$$
l_{22}=\frac{D C_{s}}{R T}
$$


Combing Eqs. (4), (5), (6), and (9), it gives

$$
v_{s 1}^{\text {wall }}-\frac{J_{s 1}}{C_{s}}=v_{s 1}^{\text {wall }}\left[1+C_{s}\left(V_{s}-V_{s}\right)\right]
$$

The ice-sublimation surface migration velocity across interface 1 is then

$$
v_{s 1}^{\text {wall }}=\frac{l_{22}\left(\frac{\Delta H_{s v}}{T} \cdot \frac{d T}{d x}+\nabla \mu_{H_{2} O, T}\right)}{C_{s}^{2}\left(V_{v}-V_{s}\right)}
$$

\section{Latent Heat Coupling (Mechanism of Water- freezing)}

The water layer is frozen on the other side of the ice layer at interface 2, as shown in Fig. 2. The mechanisms of water-freezing and ice-sublimation are combined by the spontaneous temperature gradient inside the ice layer, where $T_{l s}>T_{s v}$, by maintaining to the operation pressure slightly lower than the triple point. Since latent heat of sublimation is much greater than that of freezing, the ice growth rate of freezing would be greatly enhanced on account of the energy balance. Therefore, on account of energy

$$
J_{q 1}=J_{s 1} \cdot \Delta H_{s v}=J_{l} \cdot \Delta H_{l s}=J_{q 2}
$$

The mass flux of water across interface 2 is

$$
J_{l}=J_{s 1} \cdot \frac{\Delta H_{s v}}{\Delta H_{l s}}=v_{1}^{s 2} \cdot C_{l}
$$

The velocity of water relative to the ice front for freezing (interface 2) is then

$$
v_{1}^{s 2}=\left(v_{l}^{\text {wall }}-v_{s 2}^{\text {wall }}\right)=\frac{J_{l}}{C_{l}}
$$

The ice growth rate on the interface 2 by the mechanism of water freezing

$$
\begin{aligned}
v_{s 2}^{\text {wall }} & =\left|v_{l}^{\text {wall }}\right|+\Delta v_{s 2}=\left|v_{l}^{\text {wall }}\right|+v_{l}^{\text {wall }} \cdot C_{l}\left(V_{s}-V_{l}\right) \\
& =v_{l}^{\text {wall }}\left[1+C_{l}\left(V_{s}-V_{l}\right)\right]
\end{aligned}
$$

From Eqs.(14), (15) and (16), we obtain the result of interest

$$
v_{s 2}^{\text {wall }}=\frac{l_{22}}{C_{l}}\left(\frac{\Delta H_{s v}}{T} \cdot \frac{d T}{d x}+\nabla \mu_{H_{2} O, T}\right)\left(\frac{\Delta H_{s v}}{\Delta H_{l s}}\right)\left[1+\frac{1}{C_{l}\left(V_{s}-V_{l}\right)}\right]
$$

During the solidification of water, two processes take place simultaneously. One is the sublimation of ice on interface 1 , which will cause the ice surface to move inward from the original surface. The other is the freezing of water on interface 2. Contrary to sublimation, this mechanism will drive the ice surface to move outward from the original surface. Therefore, the net ice growth rate can be obtained by finding the difference between Eqs. (17) and (12).

$$
\begin{aligned}
v_{\text {ice, } \text {, wet }}^{\text {wall }} & =v_{s 2}^{\text {wall }}-v_{s 1}^{\text {wall }} \\
v_{\text {ice, } \text {, wet }}^{\text {wall }} & =\frac{l_{22}}{C_{l}}\left(\frac{\Delta H_{s v}}{T} \cdot \frac{d T}{d x}+\nabla \mu_{\mathrm{H}_{2} \mathrm{O}, T}\right) \\
& -\frac{l_{22}\left(\frac{\Delta H_{s v}}{T} \cdot \frac{d T}{d x}+\nabla \mu_{H_{2} \mathrm{O}, T}\right)}{C_{s}^{2}\left(V_{v}-V_{s}\right)}
\end{aligned}
$$$$
v_{\text {ice, } n e t}^{\text {wall }}=\frac{l_{22}}{C_{l}}\left(\frac{\Delta H_{s v}}{T} \cdot \frac{d T}{d x}+\nabla \mu_{H_{2} O, T}\right)\left(\frac{\Delta H_{s v}}{\Delta H_{l s}}\right)\left[1+\frac{1}{C_{l}\left(V_{s}-V_{l}\right)}\right]
$$

Since,

$$
J_{q 1}=J_{s 1} \cdot \Delta H_{s v}=U \cdot d T
$$

the overall heat transfer coefficient $U$ can be derived from Eqs. (9) and (13)

$$
U=-l_{22}\left(\frac{\Delta H_{s v}}{T} \cdot \frac{d T}{d x}+\nabla \mu_{H_{2} O, T}\right) \frac{\Delta H_{s v}}{d T}
$$

\section{RESULTS AND DISCUSSION}

The operating principle of the vacuum-freezing ice production (VFIP) method is to form a very thin ice film by flash cooling on a quiescent water film under pressure slightly lower than the triple point $(4.58 \mathrm{mmHg})$ first. This quiescent water film then turns to ice starting right from the surface underneath the thin ice film towards the bottom of the water film by the coupled mechanism of water-freezing and ice sublimation. The process repeats itself again by supplying another layer of water film on top of the first ice layer formed. Accumulating such quickly formed ice layers results in the ice-block desired. This operating process is similar to superimposing pieces of paper on a pile of paper.

The flux equations for the process of irreversible thermodynamics impose some conditions on the temperature profile at the interface. The chemical potential gradient during data reduction is neglected as $\nabla \mu_{\mathrm{H}_{2} \mathrm{O}}<<d T / d x$ near the triple point of water. Consequently, the only driving force of mass transport in the VFIP method is the temperature gradient provided by the operating pressure at the meta-stable region $(P<4.58 \mathrm{mmHg})$. The slope of $d T / d x$ in the ice layer must be negative in order to obtain heat transport to the interface, as shown in Fig. 2.

\section{Ice Growth Rates}

Replacing $d T / d x$ in Eq. (19) with $\Delta T$ and $\delta$, 


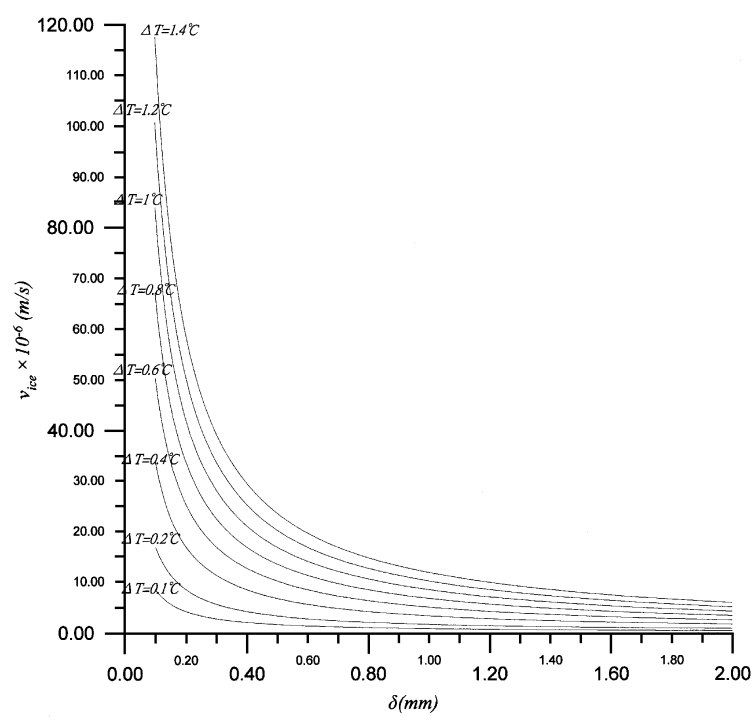

Fig. 3 Ice growth rate of the VFIP model with different ice-layer thicknesses and temperature differences

$$
\begin{aligned}
v_{\text {ice }, \text { wet }}^{\text {wall }}= & \frac{l_{22}}{C_{l}}\left(\frac{\Delta H_{s v}}{T} \frac{\Delta T}{\delta}\right)\left(\frac{\Delta H_{s v}}{\Delta H_{l s}}\right)\left[1+\frac{1}{C_{l}\left(V_{s}-V_{l}\right)}\right] \\
& -\frac{l_{22}\left(\frac{\Delta H_{s v}}{T} \cdot \frac{\Delta T}{\delta}\right)}{C_{s}^{2}\left(V_{v}-V_{s}\right)}
\end{aligned}
$$

where, $\Delta T=T_{l s}-T_{s v}$ is the temperature difference between water-freezing and ice-sublimation, and according to Fig. $2 \delta$ is the thickness of the ice layer between the ice-sublimation interface and the waterfreezing interface. Using Eq. (22), the net ice growth rates calculated for different temperature difference $\Delta T$, as a function of the ice layer thickness $\delta$, are plotted in Fig. 3. The figure shows that the ice growth rate decreases quickly as the ice layer becomes thicker and thermal resistance increases accordingly. From the outcome obtained from Fig. 3, the ice growth rate based on VFIP method deteriorates vehemently even with the condition of such a thin ice layer $\delta$. Moreover, the currently used ice production methods always accumulate ice with thickness much thicker than $\delta$ during their operating process. Therefore compared with the VFIP method, it is not difficult to realize how slow the ice growth rate is when this conventional ice production method is used at the atmospheric pressure. The ice growth rates of the conventional method operating at atmosphere (Flesland, 1995; Huige, 1972) are shown in Fig. 4. They vary from $3 \times 10^{-7} \mathrm{~m} / \mathrm{s}$ to $1.15 \times 10^{-6} \mathrm{~m} / \mathrm{s}$ with temperature driving force of 0.2 to $1^{\circ} \mathrm{C}$. On the other hand, using the same driving force provided, the ice growth rate of the present VFIP method could reach $1.15 \times 10^{-5}$

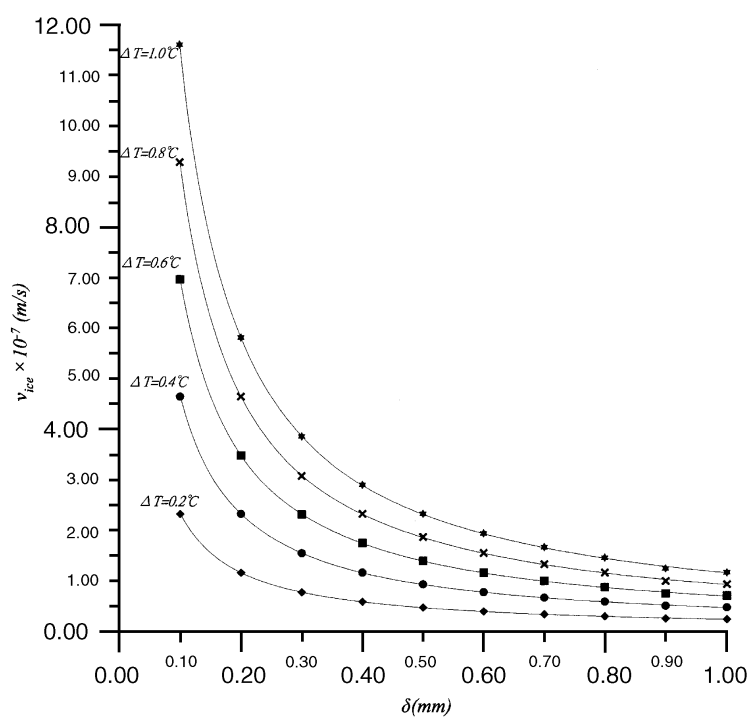

Fig. 4 Ice growth rate of the conventional ice-making model with different ice-layer thicknesses and temperature differences

$\mathrm{m} / \mathrm{s}$ to $7 \times 10^{-5} \mathrm{~m} / \mathrm{s}$, as shown in Fig. 3. The most significant and important result is that the ice growth rate of the present VFIP method is much higher than the conventional method. In the VFIP method, heat of freezing is released and conducted through the ice layer by the temperature gradient spontaneously developed by the operating pressure, and then carried away by the low pressure vapor with the required heat of sublimation. A fast ice production method with the features of spontaneous temperature gradient and latent-heat coupling is exhibited.

\section{Control Parameter}

Since the operating pressure of the present VFIP method is slightly lower than the triple point pressure $(4.58 \mathrm{mmHg})$, a pressure difference $\Delta P$ does exist during the operating process. From Fig.1, this pressure difference can be converted to a temperature difference $\Delta T$ between the temperatures of water-freezing $\left(T_{l s}\right)$ and ice-sublimation $\left(T_{s v}\right)$. The fact that $T_{l s}$ is higher than $T_{s v}$ is a unique phenomenon in the meta-stable region. This temperature difference $\Delta T$ is then the initial driving force of the VFIP method. The transformed $\Delta T$ is $0.1,0.2,0.4,0.6,0.8,1.0,1.2$, and $1.4^{\circ} \mathrm{C}$ corresponding to the operating pressure of $4.542,4.504,4.431,4.359,4.287,4.217,4.147$, and $4.079 \mathrm{mmHg}$ respectively. Accordingly, the ice growth rate increases as the temperature difference increases as shown in Fig. 3. The applicable breakthrough of VFIP is that the driving force $\Delta T$ is originally introduced by the operating pressure difference $\Delta P$ of the system. Thereby, the energy consumed is 


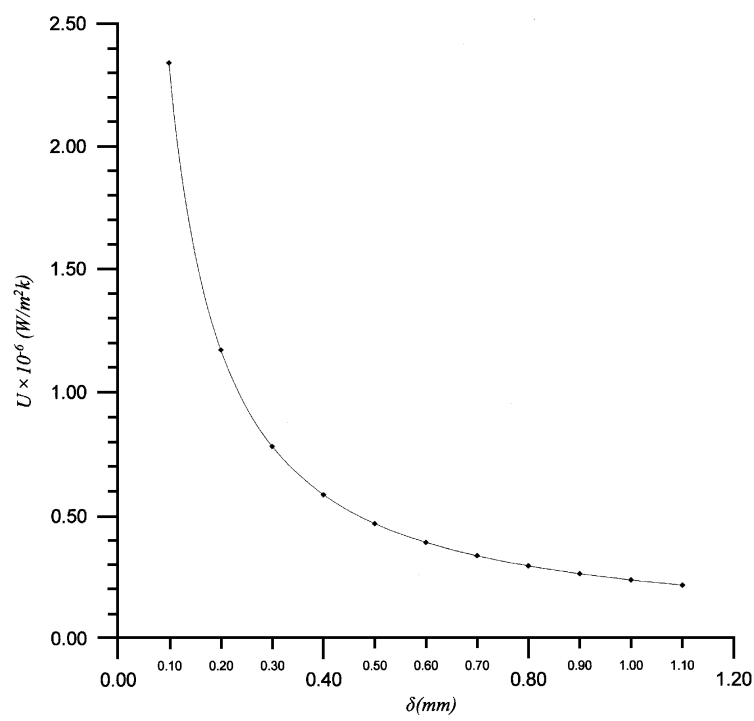

Fig. 5 Heat transfer coefficients of the VFIP method with different ice-layer thicknesses

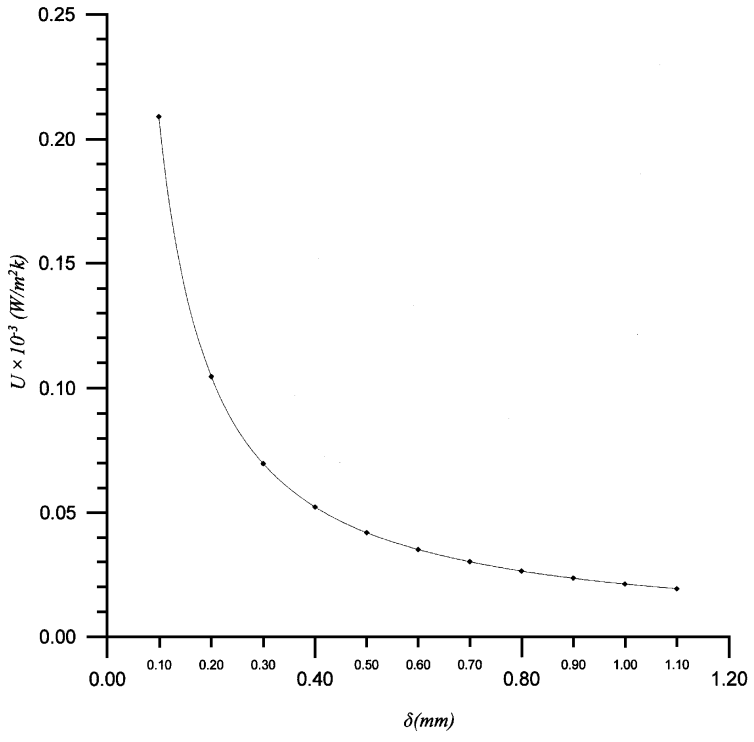

Fig. 6 Heat transfer coefficients of the conventional ice-making model with different ice-layer thicknesses

equations also apply to other systems with gradients in temperature and chemical potential (Forland et al., 1988).

\section{Equivalent Ice-Layer Thickness $\delta_{e q}$}

According to Eq. (22), the derived result for $v_{\text {ice,net }}{ }^{\text {wall }}$ is the instant ice-growth rate with respect to a specific ice-layer thickness $\delta$. In a practical operating process, the value of $\delta$ used in Eq. (22) is not fixed. It grows gradually to approach the thickness of the initially introduced water film $\delta_{l}$. Thence, the value of $v_{\text {ice,net }}$ wall calculated from Eq. (22) can not be substantially applied to real operations.

What is being anticipated from the theoretical VFIP model, to confirm the practical application of ice production process, is the average ice growth rate $v_{\text {ice,ave }}$ of the specifically provided water liquid film during solidification. To get a rigorous prediction of the ice growth rate in practical situation, concept of the equivalent ice-layer thickness $\delta_{e q}$ with respect to the specific water film thickness $\delta_{l}$ is herein introduced.

If $l_{22}$ in Eq. (22) is presumed to be kept independent of $\delta$, thereby, $v_{\text {ice, net }}{ }^{\text {wall }}=f(\Delta T, \delta)$. Thus, the average ice-growth rate $v_{\text {ice, ave }}$ for specific water film $\delta_{l}$ is

$$
v_{\text {ice, ave }}=\frac{1}{\delta} \int_{\delta_{0}}^{\delta_{1}} v_{\text {ice, } \text { net }}^{\text {wall }} \cdot d \delta
$$

where $\delta_{0}=30 \mu \mathrm{m}$ is the initial ice-layer thickness after instantaneous flash cooling at operating pressure slightly bellow $4.58 \mathrm{mmHg}$. 
Table 1 The liquid film thickness $\delta_{l}$ and the relative equivalent ice-layer thickness $\delta_{e q}$

\begin{tabular}{cccccccccc}
\hline$\delta_{1}(\mathrm{~mm})$ & 0.94 & 1.4 & 1.9 & 2.35 & 2.8 & 3.3 & 3.75 & 4.2 & 4.7 \\
$\delta_{e q}(\mathrm{~mm})$ & 0.27 & 0.366 & 0.455 & 0.538 & 0.621 & 0.7 & 0.778 & 0.853 & 0.929 \\
\hline
\end{tabular}

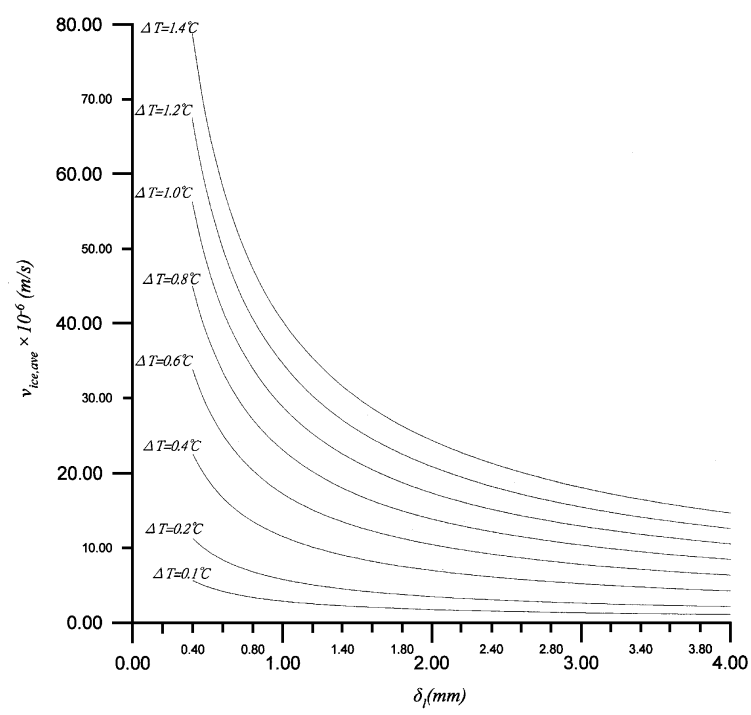

Fig. 7 Average ice growth rate of the VFIP model with different introduced water film thicknesses and temperature differences

Therefore, the equivalent ice-layer thickness $\delta_{e q}$ in accordance to $v_{\text {ice, ave }}$ can be defined as

$$
\delta_{e q}=\frac{\delta_{l}}{\ln \left|\frac{\delta_{l}}{\delta_{0}}\right|}
$$

The value of equivalent ice-layer thickness $\delta_{e q}$ and the corresponding specific water film thickness $\delta_{l}$ are listed in Table 1. Consequently, the average icegrowth rate $v_{\text {ice, ave }}$ with respect to the specific water film thickness $\delta_{l}$ is expressed as,

$v_{\text {ice, ave }}=\frac{l_{22}}{C_{l}}\left(\frac{\Delta H_{s v}}{T} \frac{\Delta T}{\delta_{e q}}\right)\left(\frac{\Delta H_{s v}}{\Delta H_{l s}}\right)\left[1+\frac{1}{C_{l}\left(V_{s}-V_{l}\right)}\right]$

According to Eq. (21), the derived $\delta_{e q}$ could be used to calculate the average heat transfer $\overline{U_{1}}$ coefficient during practical operations.

$$
\overline{U_{1}}=-l_{22}\left[\frac{\Delta H_{s v}}{T} \frac{\Delta T}{\delta_{e q}}\right] \cdot\left[\frac{\Delta H_{s v}}{\Delta T}\right]
$$

The calculated values of average $v_{\text {ice, ave }}$ from Eq. (25) for different driving forces, $\Delta T$, are plotted in Fig. 7 as a function of the introduced water film thickness $\delta_{l}$. It shows that $v_{\text {ice,ave }}$ exhibits the same decreasing trend as $v^{\text {wall }}$ ice, net , but more moderately. The results shown in Fig. 7 can be applied to the concretely assembled VFIP procedure.

\section{Cooling Coil Design Guideline}

The primary components of the practical VFIP system include a horizontal channel for water freezing, a vacuum freezing chamber to contain the water channel and the cooling coils, a water storage tank, the vacuum generating system, and the cooling system. The heat released from the ice-sublimation process should be removed, immediately, by the cooling coil as de-sublimation of the low-pressure vapor. The de-sublimation process of the cooling coil should be approached in order to get as close to zero transport resistance as possible, otherwise the ice-growth rate will deteriorate. Thence, the proper type and design of the cooling coil is the keystone of the VFIP system. In order to immediately remove the heat inside the vacuum-freezing chamber, the cooling capacity of the cooling coil should be greater than the heat releasing capacity of ice sublimation. Therefore, the necessary design guideline is

$$
\overline{U_{1}} \cdot A_{1} \cdot\left(\Delta T_{1}\right) \leq \overline{U_{2}} \cdot A_{2} \cdot\left(\Delta T_{2, l m}\right)
$$

where

$$
\Delta T_{2, l m}=\frac{\left(T_{s v}-T_{c i}\right)-\left(T_{s v}-T_{c o}\right)}{\ln \left[\frac{T_{s v}-T_{c i}}{T_{s v}-T_{c o}}\right]}
$$

$\overline{U_{2}}$ is the overall heat transfer coefficient of the cooling coil, $\Delta T_{1}=T_{l s}-T_{s v}, \Delta T_{2, l m}$ is the logarithmic mean temperature difference between $T_{s v}$ and coolant temperature, $A_{1}$ is the ice-sublimation surface area, and $A_{2}$ is the contact surface area of the cooling coil. The condition for optimal heat removal transport between the ice-sublimation surface and the coolant coil is formulated by reference to the thermal resistance method and the Gnielinsk's formula (Mills, 1995) as

$$
\frac{1}{2 \pi r_{i} \cdot \bar{h}_{c}}+\frac{\ln \left(r_{o} / r_{i}\right)}{2 \pi \cdot k_{c}} \leq \frac{\left(2 \pi r_{o} l\right) \cdot \Delta T_{2, l m}}{-l_{22}\left[\frac{\Delta H_{s v}}{\Delta T} \cdot \frac{\Delta T_{1}}{\delta_{e q}}\right] \cdot \Delta H_{s v} \cdot A_{1}}
$$

where, $\overline{h_{c}}$ is the heat transfer coefficient of coolant 
flow, $k_{c}$ is the thermal conductivity of coil pipe, $r_{o}$ and $r_{i}$ are the outer and inner radius of coil respectively, $l$ is the total length of the coolant coil, $\mathrm{Re}_{D}$ is the Reynolds number of coolant flow, and $k_{l}$ is the thermal conductivity of coolant. When the controlling variables $R e_{D}, \Delta T_{1}, \Delta T_{2, l m}, A_{1}, \delta_{e q}, k_{c}, k_{l,}, \overline{h_{c}}$, $r_{o}$, and $r_{i}$, are decided, the total length $l$ of the coolant coil is determined for proper running.

\section{CONCLUSION}

In the mysterious region of the phase diagram near the triple point, i.e. the meta-stable region, a theoretical model of a new vacuum-freezing ice production method has been proposed. The equations for processes of irreversible thermodynamics are derived to predict the ice growth rates and heat transfer coefficients with different temperature driving forces developed from various vacuum conditions. The important results of the present study are summarized as follows:

1. The ice growth rates of the VFIP method range from $1.15 \times 10^{-5} \mathrm{~m} / \mathrm{s}$ to $7 \times 10^{-5} \mathrm{~m} / \mathrm{s}$ with a driving force of 0.2 to $1^{\circ} \mathrm{C}$.

2. The ice growth rates of the VFIP method surpass those of the conventional ice production method by at least 50 times.

3. The values of the overall heat transfer coefficients $U$ for the VFIP method are much higher than the heat transfer coefficients of the traditional ice production method operating at atmosphere.

4. The average ice growth rate $v_{\text {ice,ave }}$ for practical operation is introduced with the concept of equivalent ice-layer thickness $\delta_{e q}$.

5. The design guideline for the optimal operation is established in the present study.

Extending the results of fast growties and energy-economizing features obtained, the present VFIP method may be applied not only to fishery, ice-storage air-conditioning systems, and food industries, but also to waste-water treatment and sea-water desalination

\section{NOMENCLATURE}

$A_{1} \quad$ Ice-sublimation surface area $\left(\mathrm{m}^{2}\right)$

$A_{2} \quad$ Contact surface area of coolant coil $\left(\mathrm{m}^{2}\right)$

C Concentration $\left(\mathrm{mol} / \mathrm{m}^{2}\right)$

$D \quad$ Self-diffusion coefficient $\left(\mathrm{m}^{2} / \mathrm{s}\right)$

$h_{c} \quad$ Heat transfer coefficient $\left(\mathrm{W} / \mathrm{m}^{2} \mathrm{~K}\right)$

$k_{c} \quad$ Thermal conductivity of coolant tube $(\mathrm{W} / \mathrm{mK})$

$k_{c} \quad$ Thermal conductivity of coolant $(\mathrm{W} / \mathrm{mK})$

$J_{q} \quad$ Heat flux $\left(\mathrm{J} / \mathrm{m}^{2} \mathrm{~s}\right)$

$J_{l} \quad$ Water flux $\left(\mathrm{mol} / \mathrm{m}^{2} \mathrm{~s}\right)$

$J_{s} \quad$ Ice flux $\left(\mathrm{mol} / \mathrm{m}^{2} \mathrm{~s}\right)$
$J_{v} \quad$ Vapor flux ( $\left.\mathrm{mol} / \mathrm{m}^{2} \mathrm{~s}\right)$

$l_{i j} \quad$ Phenomenological coefficient

$l \quad$ Coolant coil length $(\mathrm{m})$

$P \quad$ Pressure (mmHg)

$R \quad$ Universal constant $(\mathrm{J} / \mathrm{mol} \mathrm{K})$

$r_{o} \quad$ Outer radius of coolant coil (m)

$r_{i} \quad$ Inner radius of coolant coil (m)

$T \quad$ Temperature (K)

$T_{l s} \quad$ Water-freezing temperature (K)

$T_{s v} \quad$ Ice-sublimation temperature (K)

$v_{\text {ice, ave }} \quad$ Average ice growth rate $(\mathrm{m} / \mathrm{s})$

$v_{l} \quad$ Water velocity $(\mathrm{m} / \mathrm{s})$

$v_{s} \quad$ Ice growth rate $(\mathrm{m} / \mathrm{s})$

$v_{v} \quad$ Vapor velocity $(\mathrm{m} / \mathrm{s})$

$V \quad$ Molar volume $\left(\mathrm{m}^{3} / \mathrm{mol}\right)$

$X \quad$ Space coordinate $(\mathrm{m})$

$\Delta H_{l s} \quad$ Latent heat of freezing $(\mathrm{J} / \mathrm{mol})$

$\Delta H_{s v} \quad$ Latent heat of sublimation $(\mathrm{J} / \mathrm{mol})$

$\Delta T \quad$ Temperature difference $(\mathrm{K})$

$U \quad$ Overall heat transfer coefficient $\left(\mathrm{W} / \mathrm{m}^{2} \mathrm{~K}\right)$

$\Delta \quad$ Ice-layer thickness (m)

$\delta_{e q} \quad$ Equivalent ice-layer thickness (m)

$\delta_{l} \quad$ Introduced water film thickness (m)

$\Theta \quad$ Rate of entropy production $\left(\mathrm{W} / \mathrm{m}^{3} \mathrm{~s}\right)$

$\mu \quad$ Chemical potential $(\mathrm{J} / \mathrm{mol})$

\section{Superscripts}

$\begin{array}{ll}s & \text { Relative to ice surface } \\ v & \text { Relative to vapor phase } \\ \text { wall } & \text { Relative to wall }\end{array}$

\section{Subscripts}

$\begin{array}{ll}\text { ave } & \text { average } \\ 1 & \text { Interface-1 } \\ 2 & \text { Interface-2 } \\ \mathrm{H}_{2} \mathrm{O} & \text { water } \\ l & \text { Liquid water } \\ s & \text { Ice } \\ v & \text { water vapor }\end{array}$

\section{REFERENCE}

1. Cheng, C. Y., 1995, "High Performance In-situ Freezing-melting Process," United States Patent, No. 5388414.

2. Dickey, L. C., 1996, "Evaporation of Water from Agitated Freezing Slurries at Low Pressure", Desalination, Vol. 104, p. 155-163.

3. Flesland, O., 1995, "Freeze Concentration by Layer Crystallization," Drying Technology, Vol. 13, p. 1713-1739.

4. Forland, K. S., Forland, T., and Ratkje, S. K., 1988, Irreversible Thermodynamics Theory and Applications, John Wiley, N.Y. 
5. Fukusako, S., and Yamada, M., 1993, "Recent Advances in Research on Water-freezing and Icemelting Problems," Experimental Thermal and Fluid Science, Vol. 6, p. 99-105.

6. Huige, N. J. J., 1972, "Nucleation and Growth of Ice Crystals from Water and Sugar Solutions in Continuously Stirred Tank Crystallizers," Ph.D. Thesis, Eindhove University of Technology, The Netherlands.

7. Kuiken, G. D. C., 1994, Thermodynamics of irreversible processes, John Wiley, N.Y., p. 67.

8. Mills, A. F., 1995, Heat and Mass Transfer,
IRWIN, Chicago, p. 270.

9. Ratkje, S. K., and Flesland, O., 1995, "Modeling the Freeze Concentration Process by Irreversible Thermodynamics", J. Food Eng., Vol. 25, p. 553 567.

10. Tester, J. W., and Modell, M., 1997, Thermodynamics and Its Applications, Prentice Hall PTR, Upper Saddle River, New Jersey, p. 211.

Manuscript Received: Dec. 01, 2000

Revision Received: Feb. 20, 2001 and Accepted: Mar. 12, 2001

\title{
薄膜型真空製冰法理論模式
}

\author{
林恆毅＼cjkstart周賢福
}

國立台灣大學機械工程研究所

\begin{abstract}
摘 要
本研究提出一種結合固-液-汽三相傳輸與潛熱互用之快速眞空製冰法, 其最大特色爲於結冰過程中具有自發性溫度驅動力。以不可逆熱力學爲根基, 本文建立了此製冰法的理論模式, 完整描述此法於眞空狀態下冰層成長現象與 其熱質傳現象, 同時推導出結冰速度方程式與熱質傳方程式。本研究最大的發 現爲此製冰法的結冰速度遠高於傳統的常壓製冰法, 同時策具省能的特性, 因 此很可能用來解決目前傳統製冰法耗時與耗能的缺點。本研究並且提出了當量 結冰厚度的觀念以及系統建構的設計法則, 以作爲日後實際應用與邁向工業化 的過程的參考。
\end{abstract}

關鍵詞：眞空製冰, 結冰速度, 潛熱互用。 